\title{
NILAI EKONOMI WISATA IKAN HIU PAUS DI DESA BOTUBARANI, KABUPATEN BONE BOLANGO, PROVINSI GORONTALO
}

\section{ECONOMIC VALUE OF WHALE SHARK TOURISM IN BOTUBARANI VILLAGE, BONE BOLANGO REGENCY, GORONTALO PROVINCE}

\author{
Sri Fitriani Monoarfa ${ }^{1 *}$, Fredinan Yulianda ${ }^{2}$ Taryono $^{2}$, \& Achmad Fahrudin ${ }^{2}$ \\ ${ }^{1}$ Program Studi Pengelolaan Sumberdaya Pesisir dan Lautan, IPB University, Bogor 16680, Indonesia \\ ${ }^{2}$ Departemen Manajemen Sumberdaya Perairan, IPB University, Bogor 16680, Indonesia \\ "E-mail: monoarfa_riri@apps.ipb.ac.id
}

\begin{abstract}
The appearance of the whale shark since 2016 in the Botubarani Village, Tomini Bay, Gorontalo has become its tourist attraction and attraction that can invite tourists. This of course greatly affects the economy of the surrounding community, whale shark tourism can contribute to improving the regional economy, especially the local community. The research aims to analyze the economic value of whale shark tourism as an input in policy making based on economic analysis for the development and management of whale shark tourism in a sustainable manner in Desa Botubarani. The type of data used in this study is primary data and secondary data. The determination of respondents is done by non-probability sampling, namely purposive sampling and accidental sampling. As a guide in obtaining the information needed using a questionnaire. The method used in this study is the Travel Cost Method (TCM) and the Contingent Valuation Method (CVM). The results of the analysis of the economic value of whale shark tourism in the village of Botubarani amounted to Rp7.89.602.230 per month peak appearance (May, June, July). The calculated economic value can be the basis for making policy in advance to determine the entrance fee for shark tourism so that the management of shark tourism can run optimally and effectively.
\end{abstract}

Keywords: Gorontalo, travel cost, willingness to pay

\begin{abstract}
ABSTRAK
Kemunculan ikan hiu paus sejak 2016 di Desa Botubarani Teluk Tomini Gorontalo menjadi objek dan daya tarik wisata tersendiri yang dapat mengundang para wisatawan. Hal ini tentunya sangat memengaruhi perekonomian masyarakat sekitar, wisata ikan hiu paus dapat berkontribusi dalam peningkatan ekonomi daerah terutama masyarakat lokal. Penelitian bertujuan untuk menganalisis nilai ekonomi wisata ikan hiu paus sebagai masukan dalam pembuatan kebijakan berdasarkan analisis ekonomi untuk pengembangan dan pengelolaan wisata ikan hiu paus secara berkelanjutan di Desa Botubarani. Jenis data yang digunakan dalam penelitian ini adalah data primer dan data sekunder. Penentuan responden dilakukan secara non-probability sampling, yakni purpossive sampling dan accidental sampling. Sebagai panduan dalam memperoleh informasi yang dibutuhkan menggunakan kuisioner. Metode yang digunakan dalam penelitian ini adalah Travel Cost Method (TCM) dan Contingent Valuasi Method (CVM). Hasil analisis nilai ekonomi wisata ikan hiu paus di Desa Botubarani yaitu sebesar Rp7.894.602.230 per bulan puncak kemunculan (Mei, Juni, Juli). Nilai ekonomi yang telah dihitung dapat menjadi landasan pembuatan kebijakan, terlebih untuk menentukan biaya masuk wisata ikan hiu paus sehingga pengelolaan wisata ikan hiu paus dapat berjalan secara optimal dan efektif.
\end{abstract}

Kata Kunci: biaya perjalaan, kesediaan membayar, Gorontalo

\section{PENDAHULUAN}

Ikan hiu paus (Rhincodon typus) merupakan salah satu jenis ikan yang masuk daftar merah untuk spesies yang terancam oleh IUCN dan masuk dalam kategori Apendiks II CITES. Ikan hiu paus di Indonesia dilindungi oleh Keputusan 
Menteri Kelautan dan Perikanan Republik Indonesia Nomor 18/Kepmen-KP/2013 tentang penetapan status perlindungan penuh ikan hiu paus. Ikan terbesar di dunia ini tersebar di seluruh perairan beriklim tropis dan hangat $\left(21^{\circ} \mathrm{C}-30^{\circ} \mathrm{C}\right)$ yang ditandai dengan banyaknya produktivitas primer (banyak plankon) (Colman, 1997; Stacey et al., 2008). Pemanfaatan ikan hiu paus sebagai objek wisata telah dilakukan di beberapa daerah. Salah satu daerah yang telah menerapkan wisata ikan hiu paus adalah di perairan Desa Botubarani, Kabupaten Bone Bolango, Provinsi Gorontalo. Kemunculan ikan hiu paus di perairan Desa Botubarani diduga kuat karena ketersediaan makanan, serta kondisi perairannya berdasarkan beberapa parameter kualitas air dan perbandingan kondisi lingkungan di beberapa lokasi kemunculan ikan hiu paus (Rahman et al., 2017). Ikan hiu paus muncul ke permukaan diduga karena tertarik dengan larva ikan bermigrasi, yang disebut "nike" (Djunaidi, 2019), berbeda dengan lokasi lain. Umumnya ikan hiu paus yang muncul berada di dekat bagan untuk mencari makan, seperti kemunculan dan interaksi ikan hiu paus di perairan Kwatisore, Taman Nasional Teluk Cenderawasih (TNTC), Kabupaten Nabire sangat erat dengan ketersediaan bagan sebagai tempat untuk bermain atau mencari makan dalam waktu yang relatif lama (Suruan et al., 2018).

Sumber daya alam yang dimiliki Gorontalo sangat beragam dan beberapa di antaranya dijadikan destinasi wisata (Anugrah \& Sudarmayasa, 2017). Desa Botubarani, Teluk Tomini Gorontalo menjadi salah satu objek dan daya tarik wisata tersendiri yang mengundang para wisatawan lokal, wisatawan dalam negeri, maupun wisatawan asing. Hal ini tentunya sangat memengaruhi perekonomian masyarakat sekitar, wisata ikan hiu paus dapat berkontribusi dalam peningkatan ekonomi daerah, terutama masyarakat lokal. Kegiatan wisata ikan hiu paus di Desa Botubarani telah memberikan dampak ekonomi, meskipun dampak yang dirasakan masih dalam kategori rendah dan belum merata (Wolok, 2016). Namun, pengelolaan pariwisata yang tidak berkelanjutan merupakan salah satu ancaman terhadap ikan hiu paus. Terganggunya kelestarian ikan hiu paus dapat berdampak juga pada keberlanjutan ekonomi pengelola wisata ikan hiu paus (Quiros, 2007).

Wisata yang berbasis konservasi atau dikenal dengan ekowisata dapat menjadi opsi pembelajaran yang mengedukasi para wisatawan untuk mengubah sikap atau perilaku seseorang menjadi memiliki kepedulian, tanggung jawab dan komitmen terhadap pelestarian lingkungan (Burhanudin, 2018). Pengelolaan yang mendukung pengembangan kegiatan ekowisata diperlukan untuk mencapai tujuan ekowisata secara berkelanjutan, sehingga mendatangkan manfaat sebesar-besarnya bagi masyarakat lokal. Oleh karena itu, perlu dilakukan analisis ekonomi wisata ikan hiu paus sebagai dasar dalam mengatur kebijakan pengelolaan kawasan wisata alam ikan hiu paus yang berbasis masyarakat dan konservasi. Tujuan dari penelitian ini adalah menganalisis nilai ekonomi wisata ikan hiu paus sebagai masukan dalam pembuatan kebijakan berdasarkan analisis ekonomi untuk pengembangan dan pengelolaan wisata ikan hiu paus secara berkelanjutan di Desa Botubarani Kabupaten Bone Bolango Provinsi Gorontalo.

\section{METODE PENELITIAN}

\subsection{Lokasi dan Metode Pengumpulan Data}

Penelitian dilakukan pada bulan April sampai November 2019, di Desa Botubarani, Kecamatan Bone Bolango, Provinsi Gorontalo. Perairan Desa Botubarani masuk dalam pencadangan kawasan konservasi perairan Botubarani dengan luas 64 ha berdasarkan Keputusan Gubernur Gorontalo Nomor 141/24/IV/2019 tentang Pencadangan Kawasan Konservasi Perairan, Pesisir dan Pulau-Pulau Kecil Provinsi Gorontalo. 
Data primer diperoleh dengan melakukan observasi lapang dan wawancara dengan responden, sedangkan data sekunder diperoleh dari instansi terkait dan literaturliteratur yang relevan dengan topik penelitian ini. Penentuan responden dilakukan secara non-probability sampling, yakni accidental sampling untuk responden wisatawan. Responden yang digunakan adalah wisatawan yang secara kebetulan bertemu dengan peneliti di lokasi wisata ikan hiu paus Desa Botubarani, usia minimal 17 tahun, baik yang telah melakukan interaksi dengan ikan hiu paus maupun belum melakukan interaksi. Wawancara dilakukan untuk memperoleh informasi secara langsung melalui tanya jawab lisan sebagai pelengkap data dengan bantuan kuesioner. Jumlah sampel berjumlah 155 responden untuk wisatawan domestik dan 50 responden wisatawan mancanegara, sehingga total adalah 205 responden.

\subsection{Analisis Data}

\subsubsection{Travel Cost Method (TCM)}

Travel Cost Method (TCM) digunakan untuk mengetahui nilai kegunaan (use value) dari sumber daya melalui pendekatan (proxy) biaya perjalanan (Numberi, 2017). TCM terbagi menjadi dua tipe metode yaitu Zonal Travel Cost Method (ZTCM) dan Individual Travel Cost Method (ITCM). Kedua metode perhitungan tersebut memiliki kelebihan dan kekurangan masingmasing. Karakterisktik wisatawan menunjukkan bahwa kedatangan ke lokasi wisata ikan hiu paus Botubarani adalah kunjungan pertama kali, sehingga dalam penelitian ini dipilih analisis data menggunakan metode ZTCM. ZTCM merupakan metode yang digunakan dengan mengumpulkan informasi kunjungan berdasarkan jumlah pengunjung dari berbagai lokasi yang berbeda jarak (Isnan, 2015). Data yang diperoleh dikelompokkan menurut daerah asal pengunjung, kemudian dianalisis secara deskriptif, selanjutnya digunakan untuk menentukan/ menghitung besaran:
Menghitung derajat kunjungan per 1000 penduduk zona i:

$D=\frac{X_{i}}{N_{i}} \times 1000$

Keterangan: $D$ adalah derajat kunjungan per 1000 penduduk (kali), $X_{i}$ adalah jumlah pengunjung dari zona $i$ (orang), dan $N_{i}$ adalah jumlah penduduk zona $i$ (orang).

Estimasi fungsi permintaan:

$D=\beta_{0} X_{1}^{\beta 1} X_{2}^{\beta 2} X_{3}^{\beta 3}$

Keterangan: $D$ adalah kunjungan per 1000 penduduk (kali), $X_{1}$ adalah rata-rata biaya perjalanan (Rp), dan $X_{2} \ldots X_{3}$ adalah karakteristik sosial ekonomi pengunjung kegiatan wisata ( $\mathrm{X}_{2}$ : Umur, $\mathrm{X}_{3}$ : Pendapatan).

Transformasi intersep baru fungsi permintaan:

$\ln D=\left(\left(\beta_{0}+\beta_{2} \ln X_{2}+\beta_{3} \ln X_{3}\right)+\beta_{1} \ln X_{1}\right)$
$\ln D=\beta+\beta_{1} \ln X_{1} \ldots \ldots \ldots \ldots \ldots \ldots \ldots \ldots \ldots \ldots \ldots \ldots \ldots \ldots \ldots \ldots \ldots \ldots \ldots \ldots \ldots \ldots$

Keterangan: $D$ adalah jumlah kunjungan (kali), $X_{1}$ adalah rata-rata biaya perjalanan (Rp), dan $X_{2} \ldots X_{3}$ adalah karakteristik sosial ekonomi pengunjung kegiatan wisata $\left(\mathrm{X}_{2}\right.$ : Umur, $\mathrm{X}_{3}$ : Pendapatan).

Transformasi fungsi permintaan (c) ke fungsi permintaan asal:

$D=\beta^{\prime} X_{1}^{\beta 1}$

Keterangan: $D$ adalah jumlah kunjungan (kali) dan $X_{1}$ adalah rata-rata biaya perjalanan (Rp).

Fungsi permintaan:

$F(D)=\left(\frac{D}{a}\right)^{\frac{1}{b_{1}}}$

Keterangan: $D$ adalah jumlah kunjungan (kali), $a$ adalah konstanta, bl adalah koefisien variabel. 
Menghitung elastisitas permintaan:

$$
\left(\frac{\Delta Q}{\Delta P}\right) \times\left(\frac{P}{Q}\right)
$$

Keterangan: $Q$ adalah rata- rata kunjungan (kali) dan $P$ adalah rata- rata harga (Rp).

Menduga nilai WTP berdasarkan biaya perjalanan:

$$
\frac{\left(\sum T C_{1}+\sum T C_{2}\right)}{\left(\sum n_{1}+\sum n_{2}\right)}
$$

Keterangan: $T C_{1}$ adalah jumlah biaya perjalanan per individu untuk wisatawan domestik (Rp), $T C_{2}$ adalah jumlah biaya perjalanan per individu untuk wisatawan mancanegara (Rp), $n$ adalah jumlah responden (orang).

\subsubsection{Contingent Valuation Method (CVM)}

Pendekatan CVM dilakukan dengan wawancara langsung pada responden tentang seberapa nilai membayar/Willingness To Pay (WTP). Menurut Hanley \& Spash (1993) WTP atau kesediaan untuk membayar adalah kesediaan individu untuk membayar terhadap suatu kondisi lingkungan atau penilaian terhadap sumber daya alam dan jasa alami dalam rangka memperbaiki kualitas lingkungan. Hal penting dalam CVM adalah kuesioner yang dirancang dengan baik (Indab, 2016). Kuisioner digunakan sebagai instrumen pengumpulan data dengan teknik wawancara, dengan merancang pertanyaan untuk memperoleh informasi yang diinginkan.

Dalam penelitian ini yang dimaksud dengan kemauan membayar (WTP) yaitu kesediaan responden untuk pengelolaan wisata ikan hiu paus dengan satuan harga (Rupiah). Estimasi WTP dapat dilakukan dengan menduga hubungan antara WTP dengan karakteristik responden yang mencerminkan tingkat penghargaan wisatawan terhadap wisata ikan hiu paus dengan menggunakan rumus:

$$
W T P=\beta_{0}+\sum_{i=1}^{n} \beta_{1} X_{i}
$$

Keterangan: WTP adalah kemampuan membayar pengguna terhadap suatu sumber daya (Rp), dan $X_{i}$ adalah parameter pengukuran ke- $i$ (seperti biaya perjalanan, jarak, pendapatan, umur, dan pendidikan).

Rata-rata WTP (MWTP) dapat diduga dengan menggunakan nilai rata-rata dari penjumlahan keseluruhan nilai WTP dibagi jumlah responden. Dugaan Rataan WTP dihitung dengan rumus:

$M W T P=\sum \frac{Y_{i}}{n}$

Keterangan: $M W T P$ adalah rata-rata WTP $(\mathrm{Rp}), Y_{i}$ adalah nilai WTP ke- $i(\mathrm{Rp}), n$ adalah jumlah responden (orang), dan $i$ adalah responden ke-i yang bersedia membayar $(i=$ $1,2,3, \ldots, n)$

Setelah mengetahui tingkat WTP yang dihasilkan per individu, total nilai ekonomi sumber daya dihitung dengan mempertimbangkan daya dukung untuk mengatur agar wisata ikan hiu paus dapat berkelanjutan, dengan rumus:

$W T P=M W T P \times D D W$

Keterangan: TWTP adalah total nilai ekonomi (Rp), MWTP adalah rata-rata nilai WTP (Rp), DDW adalah daya dukung wisata.

Metode daya dukung yang digunakan merupakan modifikasi dari Yulianda (2019) dengan menggunakan rumus:

$D D W=K \times\left(\frac{w_{t}}{w_{p}}\right)$

Keterangan: $D D W$ adalah daya dukung wisata (orang/hari), $K$ adalah potensi pengunjung (12 orang), $W_{t}$ adalah waktu yang disediakan kawasan untuk kegiatan wisata dalam 1 hari (6 jam), $W p$ adalah waktu yang dihabiskan oleh pengunjung untuk melihat ikan hiu paus (3 jam). 


\section{HASIL DAN PEMBAHASAN}

\subsection{Karakteristik Pengunjung Wisata Ikan Hiu Paus Desa Botubarani}

Karakteristik pengunjung wisata ikan hiu paus Botubarani menurut asal kedatangannya terbagi menjadi dua, yakni wisatawan domestik dan wisatawan mancanegara. Pengunjung yang datang ke wisata ikan hiu paus Desa Botubarani paling banyak adalah wisatawan domestik, yakni sebesar $77 \%$ responden. Sebanyak 26\% responden dari dalam Provinsi Gorontalo dan dari luar Provinsi Gorontalo sebanyak $51 \%$ responden. Wisatawan mancanegara sendiri sebesar $23 \%$ responden. Wisata ikan hiu paus Botubarani merupakan wisata yang cocok untuk semua kalangan. Hal ini, dapat dilihat persentase kedatangan wisatawan yang datang baik laki-laki dan perempuan tidak berbeda jauh, wisatawan laki-laki sebanyak $55 \%$ responden dan perempuan sebanyak $45 \%$ responden.

Wisatawan yang datang ke wisata ikan hiu paus didominasi oleh rentang umur 20 tahun sampai 30 tahun untuk wisatawan domestik (Figure 1a) dan wisatawan mancanegara (Figure 1b). Menurut Departemen Kesehatan RI (2009) rentang umur 20 tahun sampai 30 tahun masuk dalam kategori remaja akhir dan dewasa awal. Hal ini menunjukan, wisatawan sebagian besar berada pada usia produktif. Umur secara tidak langsung dapat memengaruhi permintaan wisatawan untuk mengunjungi objek wisata, karena umur berkaitan dengan waktu luang dan aktivitas serta kemampuan wisatawan untuk melakukan kunjungan wisata. Selain itu, umur menjadi faktor yang menentukan pola pikir seseorang dalam menentukan jenis barang dan jasa yang akan dikonsumsinya, termasuk konsumsi ke tempat-tempat wisata.

Berdasarkan tingkat pendidikan (Figure 3), karakteristik responden didominasi oleh Sarjana baik pada wisatawan domestik maupun wisatawan mancanegara, tingkat pendidikan terendah untuk kedua wisatawan adalah pada tingkatan Sekolah

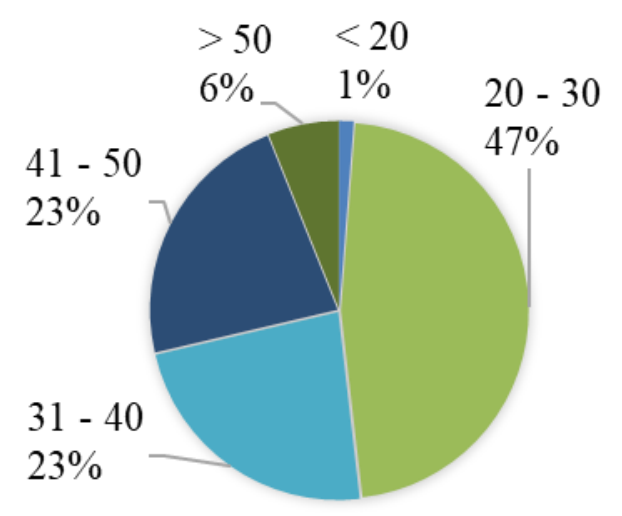

(a)

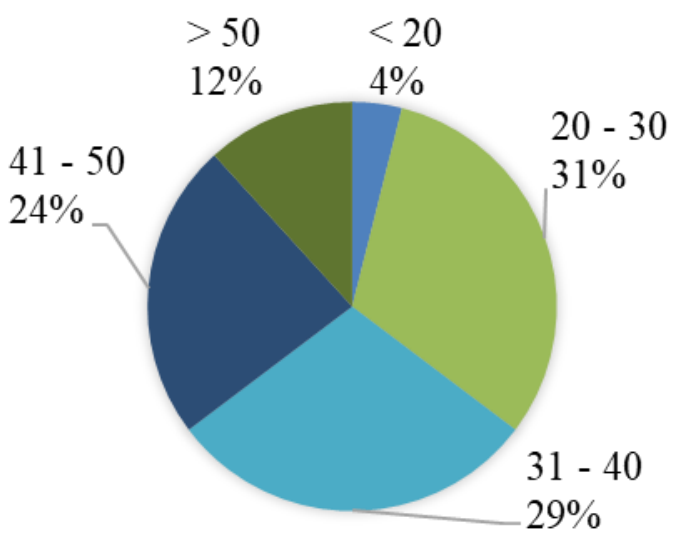

(b)

Figure 1. Percentage of age of Botubarani whale shark tourists (a) domestic (b) foreign.

Menengah Atas (SMA). Sisanya memiliki tingkat pendidikan dijenjang Diploma, Magister, dan Sarjana.

Kegiatan yang dilakukan wisatawan ketika datang ke wisata ikan hiu paus Botubarani beragam. Kegiatan paling utama adalah melihat dari atas perahu (watching) sebesar 59\% (Figure 3). Kemunculan ikan hiu paus yang sampai saat ini belum diketahui kepastian munculnya menyebabkan pengunjung ada yang langsung kembali ketika diinfokan bahwa ikan hiu paus tidak muncul, ada pula yang memilih untuk menunggu hingga ikan hiu paus muncul. Sebesar $22 \%$ responden memilih untuk menunggu sambil sekadar menikmati pemandangan maupun membeli cemilan setempat, seperti pisang goroho. Wisata ikan hiu paus terus dikem- 


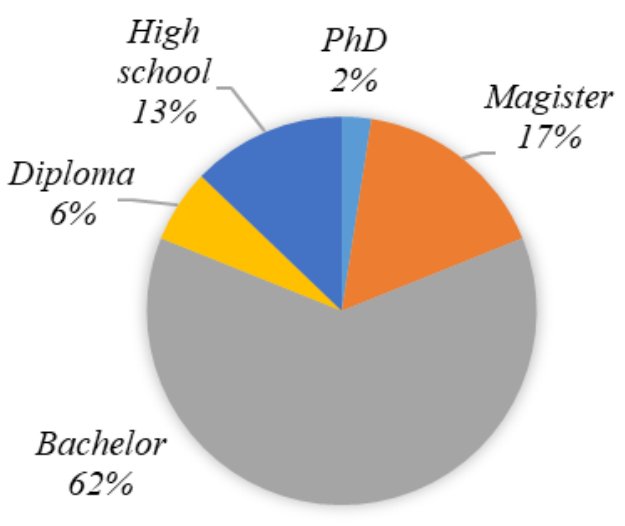

(a)

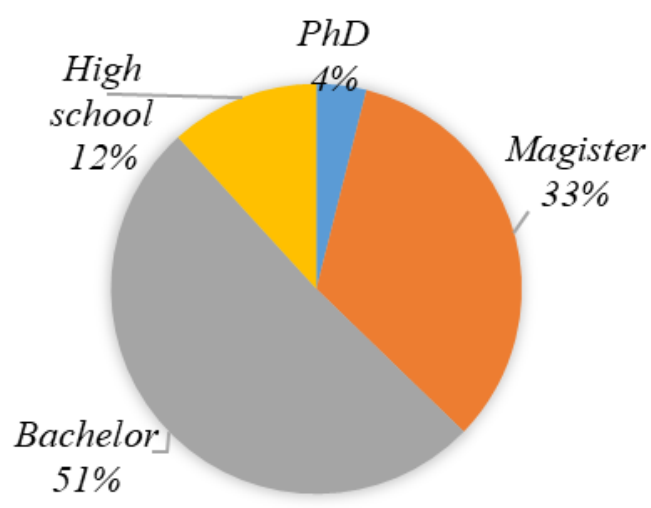

(b)

Figure 2. Percentage of education level of whale shark tourist tourists (a) domestic (b) foreign.

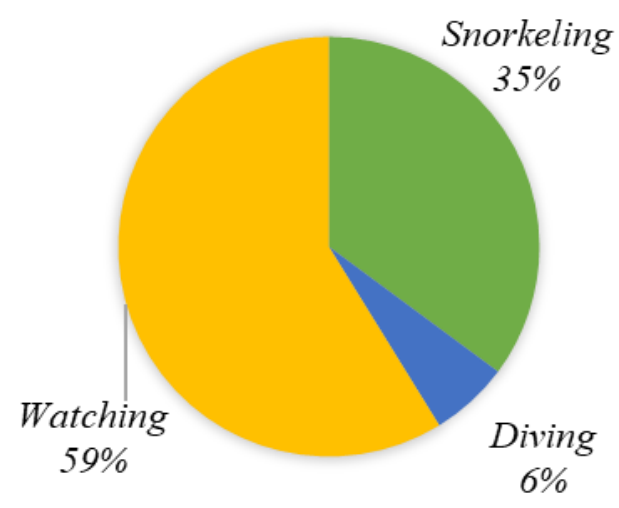

Figure 3. Activities performed.

bangkan oleh pemeritah daerah dengan disediakannya whale shark center sebagai pusat informasi, di mana pengunjung bisa mendapat informasi mengenai ikan hiu paus yang ada di perairan Desa Botubarani. Informasi yang disediakan beragam, baik melalui tulisan maupun visual. Dimulai dari info monitoring kemunculan sampai kegiatan pengukuran dan identifikasi ikan hiu paus di Desa Botubarani.

Pengunjung yang datang ke wisata ikan hiu paus Desa Botubarani tidak semua menjadikannya sebagai tujuan utama. Pengunjung yang tidak menjadikan wisata ikan hiu paus Botubarani sebagai destinasi utamanya biasanya memiliki tujuan lain seperti urusan pekerjaan, bertemu keluarga, atau mengunjungi tempat liburan lainnya. Wisatawan domestik sebesar $57 \%$ responden menjadikan wisata ikan hiu paus Botubarani sebagai destinasi utama yang akan dikunjungi dalam perjalanan wisatanya. Berbeda dengan wisatawan domestik, sebesar $61 \%$ responden wisatawan mancanegara menjawab tidak menjadikan wisata ikan hiu paus Botubarani sebagai wisata utamanya. Hal ini disebabkan karena wisatawan mancanegara menjadikan Gorontalo sebagai transit dari perjalanan mereka dan mendapatkan informasi mengenai wisata ini ketika tiba di Gorontalo. Walaupun bukan menjadi tujuan utama bagi wisatawan mancanegara tetapi berdasarkan hasil wawancara pengalaman wisata yang dirasakan adalah positif, begitu pula dengan wisatawan domestik.

\subsection{Faktor-Faktor yang Memengaruhi Jumlah Kunjungan Responden untuk Wisata Ikan Hiu Paus Desa Botubarani}

Ekowisata ikan hiu paus di Desa Botubarani yang dimulai dari tahun 2016 ini sudah memiliki beberapa fasilitas, seperti jalan masuk, menara pengawas, panggung informasi, dan kamar mandi. Wisata ini punya fasilitas kamar mandi, tapi belum memiliki toilet umum. Lokasi wisata yang tidak terlalu jauh dari pusat kota memudahkan transportasi untuk menuju ke tempat wisata. Pengujian terhadap model regresi dilakukan untuk mengetahui besarnya pengaruh faktor-faktor yang memengaruhi jumlah 
kunjungan responden untuk wisata ikan hiu paus ke Desa Botubarani.

\subsubsection{Wisatawan Domestik}

Wisatawan domestik berdasarkan hasil regresi menunjukkan bahwa variabel biaya perjalanan memiliki nilai koefisien negatif. Hal ini menunjukkan bahwa variabel tersebut berbanding terbalik terhadap permintaan wisata ikan hiu paus di perairan Botubarani. Artinya, semakin tinggi biaya perjalanan wisatawan maka permintaan terhadap wisata akan menurun (Figure 6). Variabel yang memiliki nilai positif artinya memiliki variabel tersebut memiliki nilai positif terhadap permintaan wisata di desa Botubarani, di mana berdasarkan hasil analisis uji regresi variabel umur dan pendapatan mempunyai nilai positif. Artinya, dengan bertambahnya umur dan pendapatan wisatawan, kemauan untuk berkunjung ke tempat wisata ikan hiu paus desa Botubarani juga meningkat. Model yang dihasilkan adalah sebagai berikut:

$\mathrm{D}=9,81\left(\right.$ Biaya $\left.^{-1,42}\right)\left(\mathrm{Umur}^{0,16}\right)$ (Pendapatan ${ }^{0,31}$ )

Model persamaan regresi untuk wisatawan domestik dengan nilai $\mathrm{R}^{2}$ sebesar $33 \%$ dipercaya untuk dapat menjelaskan fungsi permintaan wisata pada ekowisata ikan hiu paus oleh variabel bebas dan $67 \%$, sisanya dijelaskan oleh variabel yang tidak diikutserta- kan. Nilai $\mathrm{R}^{2}$ yang rendah tidak menjadi masalah, penelitian yang berhubungan dengan objek lingkungan dapat mentolerir nilai $\mathrm{R}^{2}$ sebesar $15 \%$, karena penelitian lingkungan melibatkan perilaku manusia, sehingga nilai $\mathrm{R}^{2}$ sebesar $15 \%$ masih dapat ditoleransi (Mitchell \& Carson, 1989; Khan et al., 2014; Fauzi, 2014). Wisata ikan hiu paus Botubarani dikatakan masuk dalam permintaan elastis, di mana permintaan kunjungannya terpengaruh oleh naik turunnya harga. Ratarata nilai elastisitas permintaan untuk wisata ikan hiu paus Botubarani adalah $\pm 1,65(>1)$, maka artinya ketika total biaya naik atau turun sebesar $1 \%$, maka permintaan kunjungan naik atau turun sebesar $1,65 \%$.

\subsubsection{Wisatawan Mancanegara}

Wisatawan mancanegara berdasarkan hasil regresi menunjukkan bahwa biaya perjalanan dan karakteristik wisatawan mancanegara tidak memengaruhi jumlah kunjungan. Hal ini diduga karena ada wisata kunjungan lain, salah satunya Togean, sehingga wisata ikan hiu paus Botubarani bukan menjadi tujuan utama wisata dari wisatawan mancaranegara.

Wisata ikan hiu paus Botubarani untuk wisatawan mancanegara masuk dalam permintaan inelastis, di mana permintaan kunjungannya tidak terpengaruh oleh naik turunnya harga. Rata-rata nilai elastisitas permintaan biaya terhadap jumlah kunjungan untuk wisata ikan hiu paus Botubarani

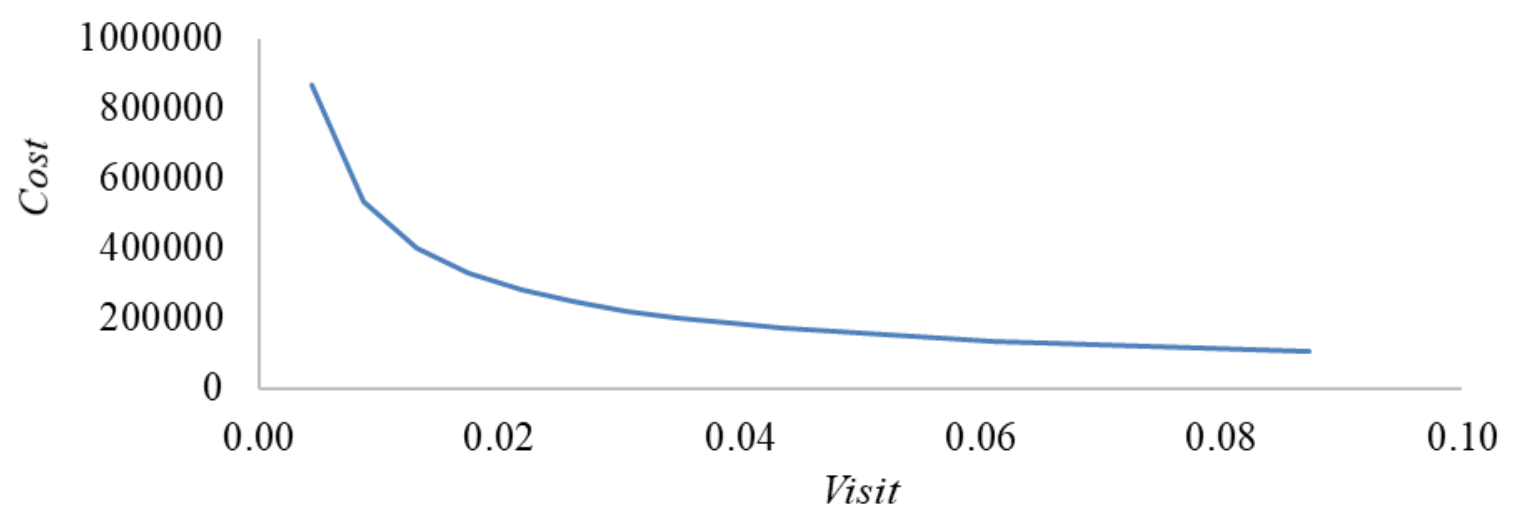

Figure 6. Travel cost demand curve against the number of visits on whale shark tours for domestic tourists 
adalah $\pm 0,21(<1)$, artinya ketika total biaya naik atau turun sebesar $1 \%$ maka permintaan kunjungan naik atau turun sebesar $0,21 \%$. Walaupun bukan menjadi tujuan utama, tetapi ikan hiu paus dianggap masuk dalam kategori barang superior (luxury goods). Ikan hiu paus sendiri memiliki kualitas tinggi dengan statusnya yang langka sehingga mampu memberikan prestise tersendiri bagi pengunjung wisata ikan hiu paus.

\subsection{Faktor-faktor yang Memengaruhi WTP Pengunjung terhadap Wisata Ikan Hiu Paus Desa Botubarani}

Analisis data nilai keberadaan ekowisata ikan hiu paus menggunakan beberapa variabel diantaranya umur, pendidikan, pendapatan, jarak, dan biaya perjalanan.

\subsubsection{Wisatawan Domestik}

Wisatawan domestik variabel umur $(p$-value $=0,02)$ dan pendapatan $(p$-value $=$ 0,003 ) signifikan. Wisatawan yang memiliki tingkat pendapatan yang tinggi cenderung akan memberikan kesediaan membayar yang tinggi dibandingkan dengan responden yang pendapatannya rendah. Variabel pendapatan memiliki nilai koefisien positif, artinya semakin tinggi pendapatan maka semakin tinggi kesediaan membayar. Pendapatan yang tinggi akan membuat responden memiliki dana lebih untuk membayar dalam upaya konservasi ikan hiu paus. Sementara itu, variabel umur mempunyai hubungan negatif terhadap nilai WTP wisatawan. Hal ini menunjukkan bahwa semakin rendah umur wisatawan maka semakin tinggi nilai yang bersedia dibayarkan untuk menjaga keberadaan wisata ikan hiu paus di Desa Botubarani. Karakteristik responden wisatawan domestik memiliki rentang umur yang relatif muda, yakni 20-30 tahun. Kesediaan untuk membayar lebih (WTP) diduga karena merasakan mendapat pengalaman bertemu dengan ikan hiu paus dan ingin mengulang pengalaman tersebut. Model yang dihasilkan adalah sebagai berikut:
$\mathrm{D}=8,13\left(\right.$ Umur $\left.^{-0,54}\right)\left(\right.$ Pendidikan $\left.^{0,25}\right)$

$\left(\right.$ Pendapatan $\left.^{0,25}\right)\left(\right.$ Jarak $\left.^{0,01}\right)\left(\right.$ Biaya $\left.^{0,04}\right)$

\subsubsection{Wisatawan Mancanegara}

Wisatawan mancanegara variabel yang signifikan adalah biaya perjalanan dengan $P$-value $=0,04(\alpha<0,05)$. Wisatawan mancanegara pada variabel biaya perjalanan memiliki hubungan negatif dengan WTP. Semakin rendah biaya perjalanan wisatawan maka semakin tinggi nilai yang bersedia dibayarkan untuk menjaga keberadaan wisata ikan hiu paus di Desa Botubarani. Lokasi wisata ikan hiu paus Desa Botubarani yang tidak terlalu jauh dari pusat kota menjadikan wisata ini mudah dikunjungi. Pertimbangan biaya perjalanan yang dikeluarkan akan meningkatkan kesediaan membayar akibat adanya penambahan atau pengurangan biaya perjalanannya. Model yang dihasilkan adalah sebagai berikut:

$\mathrm{D}=10,46\left(\right.$ Umur $\left.^{-0,29}\right)\left(\right.$ Pendidikan $\left.^{1,098}\right)$ $\left(\right.$ Pendapatan $\left.^{0,098}\right)\left(\mathrm{Jarak}^{0,008}\right)\left(\right.$ Biaya $\left.^{-0,15}\right)$

\subsection{Nilai Manfaat Langsung}

Nilai manfaat langsung ikan hiu paus dilihat dari fungsinya yang dimanfaatkan untuk kegiatan wisata. Biaya perjalanan dapat menduga nilai ekonomi sebuah komoditas yang tidak memiliki nilai pasar (Bergin \& Price, 1994; Limaei et al., 2014). Wisatawan yang sebenarnya berasal dari lokasi yang jauh dari lokasi wisata yang ingin dituju mendapatkan manfaat yang sama atau selisih biaya dalam teori ekonomi dianggap sebagai representasi dari permintaan (demand) wisatawan terhadap wisata tersebut (Adrianto, 2006).

Hasil perhitungan biaya perjalanan yang dikeluarkan wisatawan berdasarkan zona asal kedatangan dan masing-masing individu, diperoleh total biaya perjalanan per individu Rp4.730.332,00, sedangkan nilai yang dibayarkan rata-rata per individunya sebesar Rp2.308.897,00 untuk wisatawan domestik. Oleh karena itu, diketahui bahwa nilai surplus bagi konsumen per wisatawan 
sebesar Rp2.421.435,00 per musim puncak kemunculan. Surplus konsumen dapat diartikan sebagai wakil dari nilai kemampuan konsumen untuk membayar terhadap lokasi wisata. Hal ini berarti wisatawan sebenarnya masih bersedia membayar lebih untuk melakukan kegiatan ekowisata ikan hiu paus Desa Botubarani. Demi menjaga keberlanjutan maka dipertimbangkan daya dukung untuk wisata ikan hiu paus Botubarani.

Nilai manfaat langsung untuk wisata ikan hiu paus Botubarani berdasarkan daya dukung cukup tinggi, yakni sebesar Rp7.379.317.463,00 per bulan puncak kemunculan (Mei, Juni, Juli). Hal ini diduga karena kedatangan wisatawan berasal dari luar Desa Botubarani, sehingga biaya perjalanan yang dihasilkan juga besar. Nilai manfaat ini masih bisa bertambah jika kegiatan wisata bisa dikembangkan sesuai dengan prinsip ekowisata yang sebenarnya, karena hal yang perlu dipertimbangkan adalah wisata ini yang berada di dalam pencadangan kawasan konservasi perairan daerah. Ekowisata berbasis masyarakat sebaiknya dilakukan untuk melestarikan ikan hiu paus serta dapat meningkatkan status sosial ekonomi masyarakat (Quiros, 2007).

\subsection{Nilai Manfaat Keberadaan}

Nilai manfaat keberadaan (eksistensi) ekowisata ikan hiu paus di Desa Botubarani dianalisis menggunakan CVM dengan melihat seberapa besar kesediaan membayar seseorang/WTP terhadap keberadaan dan jasa yang diterima dari wisata ini. Pada penelitian ini digunakan pendekatan kepada wisatawan dengan melihat seberapa besar kesediaan membayar mereka dengan pendeka- tan biaya tiket masuk lokasi wisata. Teknik pendekatan yang dilakukan dengan metode pertanyaan bidding game wisatawan diberikan penawaran harga hingga mencapai kesepakatan harga yang bersedia dibayarkan.

Nilai rata-rata WTP dari wisatawan domestik sebesar Rp115.871 per satu kali masuk dengan asumsi wisatawan berkunjung satu kali dalam setahun pada bulan puncak kemunculan dikali dengan daya dukung wisata ikan hiu paus Desa Botubarani sebesar 1560 orang, sehingga nilai manfaat keberadaan dari wisatawan domestik sebesar Rp180.758.367 per bulan puncak kemuncul an. Nilai rata-rata WTP dari wisatawan mancanegara Rp214.440 per satu kali masuk dengan asumsi sama seperti wisatawan domestik yakni wisatawan berkunjung satu kali dalam setahun dikali daya dukung kawasan, sehingga nilai keberadaan dari wisatawan mancanegara sebesar Rp334.526.400 per bulan puncak kemunculan. Jumlah dari WTP wisatawan domestik dan WTP wisatawan mancanegara merupakan total nilai manfaat keberadaan wisata ikan hiu paus di Desa Botubarani, yaitu sebesar Rp515.284.767 per bulan puncak kemunculan (Table 1).

\subsection{Nilai Ekonomi Wisata Ikan Hiu Paus Desa Botubarani}

Nilai ekonomi total merupakan penjumlahan nilai ekonomi keseluruhan dari manfaat wisata ikan hiu paus yang telah diidentifikasi dan dikuantifikasi. Nilai wisata ikan hiu paus di Desa Botubarani adalah penjumlahan dari nilai manfaat langsung dan nilai manfaat keberadaan (Table 2). Nilai ekonomi wisata ikan hiu paus di Desa

Table 1. The total value of the existence benefits of whale shark tourism in the village of Botubarani.

\begin{tabular}{lcr}
\hline \multicolumn{1}{c}{ Respondent } & $\begin{array}{c}\text { Average WTP } \\
(\text { Rp/ind })\end{array}$ & $\begin{array}{c}\text { Total WTP with carrying capacity } \\
\text { (Rp/peak season) }\end{array}$ \\
\hline Domestic & 115.871 & 180.758 .367 \\
Foreign & 214.440 & 334.526 .400 \\
Total & & 515.284 .767 \\
\hline
\end{tabular}


Table 2. The economic value of whale shark tourism in Botubarani Village.

\begin{tabular}{lr}
\hline Category & Net Value $(\mathrm{Rp})$ \\
\hline Direct use value & 7.379 .317 .463 \\
Existence value & 515.284 .767 \\
\hline Total & 7.894 .602 .230 \\
\hline
\end{tabular}

Botubarani seluas 64 ha diperoleh sebesar Rp7.894.602.230/bulan puncak kemunculan atau rata-rata sebesar Rp123.353.160/ha/ bulan puncak kemunculan.

Hasil ini menunjukkan bahwa wisata ikan hiu paus di Desa Botubarani memiliki peranan yang cukup besar baik yang dirasakan secara langsung ataupun keberadaannya. Pembangunan kawasan konservasi laut merupakan investasi yang tidak ternilai harganya dan memberikan kontribusi kepada masyarakat, baik secara langsung maupun tidak langsung (Thur, 2010; Reuchlin \& McKenzie, 2015). Manfaat yang diperoleh dari nilai alami keanekaragaman hayati salah satunya adalah jasa ekosistem (Sandler, 2012). Nilai jasa ekosistem dari ikan hiu paus yang dimanfaatkan sebagai objek wisata jauh lebih besar daripada nilai jika ditangkap dan dikonsumsi (CisnerosMontemayor et al., 2013; Cagua, 2014; Anna \& Saputra, 2017).

\section{KESIMPULAN}

Pengunjung yang datang di wisata ikan hiu paus Desa Botubarani terdiri dari wisatawan domestik dan mancanegara serta diminati semua kalangan baik perempuan maupun laki-laki yang memiliki usia produktif. Nilai ekonomi wisata ikan hiu paus Desa Botubarani sebesar Rp7.894.602.230,00/ bulan puncak kemunculan, yakni bulan Mei, Juni, dan Juli. Nilai ekonomi yang telah dihitung dapat menjadi landasan pembuatan kebijakan terlebih untuk menentukan biaya masuk wisata ikan hiu paus sehingga pengelolaan wisata ikan hiu paus dapat berjalan secara optimal dan efektif. Perlu dilakukan penelitian lanjutan untuk evaluasi biaya pengelolaan sebagai bahan desain pengelolaan ekowisata ikan hiu paus Desa Botubarani.

\section{UCAPAN TERIMA KASIH}

Terima kasih Penulis sampaikan kepada Conservation Strategy Fund (CSF) dan The David and Lucile Packard Foundation's telah mensponsori penelitian ini, para enumerator dalam pengambilan data (Nikma, Ai, Fahri, Dadang, dan Anto), serta masyarakat pesisir Desa Botubarani yang telah menerima kami dengan baik.

\section{DAFTAR PUSTAKA}

Adrianto, L. 2006. Pengantar penilaian ekonomi sumberdaya pesisir dan lautan. Bogor (ID): FPIK-IPB. 78 p.

Anna, Z. \& D. Saputra. 2017. Economic valuation of whale shark tourism in Cenderawasih Bay National Park, Papua, Indonesia. BIODIV, 18(3): 1026-1034. https://doi.org/10.13057/biodiv/d180 321

Anugrah, K. \& I.W. Sudarmayasa. 2017. Pembangunan pariwisata daerah melalui pengembangan sumber daya manusia di Gorontalo. JUMPA, 4(1): 33-46.

https://doi.org/10.24843/JUMPA.201 7.v04.i01.p03

Bergin, J. \& C. Price. 1994. The travel cost method and landscape quality. Landscape Research, 19(1): 21-23. https://doi.org/10.1080/01426399408 706416

Burhanudin, M.F. 2018. Role integration on tourism: business model of shark attraction ecotourism in Tinabo Island Takabonerate. Prosiding Simposium Nasional Hiu Pari Indonesia Ke-2. 331-338 pp. http://ejournalbalitbang.kkp.go.id/index.php/prosidi ngprp/article/download/7548/6085 
Cagua, E.F., N. Collins, J. Hancock, \& R. Rees. 2014. Whale shark economics: a valuation of wildlife tourism in South Ari Atoll, Maldives. Peer J 2, e515.

https://doi.org/10.7717/peerj.515

Convention on International Trade in Endangered Species of Wild Fauna and Flora (CITES). 2007. Appendices I, II \& III of CITES. www.cites.org/eng/app/appendices.p hp

Colman, J.G. 1997. A review of the biology and ecology of the whale shark. J. of Fish Biology, 51(6): 1219-1234. https://doi.org/10.1111/j.10958649.1997.tb01138.x

Cisneros-Montemayor, A.M., M. BarnesMauthe, D. Al-Abdulrazzak, E. Navarro-Holm, \& U.R. Sumaila. 2013. Global economic value of shark ecotourism: implications for conservation. Oryx, 47(3): 381-388. https://doi.org/10.1017/S0030605312 001718

Djunaidi, A., J. Jompa, Nadiarti, A. Bahar, A. Sianipar , A.W. Hasan, I.S. Alaydrus, \& M. Erdmann. 2019. Potential tourism development for whale shark (Rhincodon typus) watching in eastern Indonesia. IOP Conf. Ser.: Earth Environ. 7-8 Agustus 2018. 1-12 pp. https://doi.org/10.1088/17551315/253/1/012043

Fauzi, A. 2014. Valuasi Ekonomi dan Penilaian Kerusakan Sumberdaya Alam dan Lingkungan. IPB Press. Jakarta (ID). 246 p.

Hanley, N. \& C.L. Spash. 1993. Cost benefit analysis and the environment. Edward Elgar Pub. English. 288 p.

International Union for Conservation of Nature (IUCN). 2018. The IUCN red list of threatened species. http://www.iucnredlist.org

Indab, A.L. 2016. Willingness to pay for whale shark conservation in
Sorsogon, Philippines. Springer, 6: 93-128. https://doi.org/10.1007/978981-10-0141-3_6

Isnan, W. 2015. Teknik perhitungan tarif masuk kawasan wisata alam. Info teknis EBONI, 12(2): 65-74. http://doi.org/10.20886/buleboni.505 5

Keputusan Gubernur Gorontalo (Kep-Gub) Nomor 141 / 24 / IV /2019 tentang Pencadangan Kawasan Konservasi Perairan, Pesisir dan Pulau-Pulau Kecil Provinsi Gorontalo.

http://bappeda.gorontaloprov.go.id/in stitution/file_share/PERDA-

RZWP3K-ProvinsiGorontalo_106_952.pdf

Khan, H., F. Ali, H. Khan, M. Shah, \& S. Shoukat. 2014. Estimating willingness to pay for recreational services of two public parks in Peshawar pakistan. Environmental Economics, 5(1): 21-26.

https://businessperspectives.org/pdfp roxy.php?item_id:5676

Limaei, S.M., H. Ghesmati, R. Rashidi, \& N. Yamini. 2014. Economic evaluation of natural forest park using the travel cost method (case study; Masouleh forest park, north of Iran. J. of Forest Science, 60(6): 254-261. https://doi.org/10.17221/84/2013-JFS

Mitchell, R.C. \& R.T. Carson. 1989. Using Surveys to Value Public Goods: The Contingent Valuation Method. Resources for the Future. Washington, D.C. (US). 484 p.

Numberi, A., M. Kamal, A. Fahrudin, W. Abraham,. Manumpil \& J. Manan. 2018. Peluang kemunculan hiu paus (Rhincodon typus smith, 1828) di Perairan Kwatisore Taman Nasional Teluk Cenderawasih. Prosiding Simposium Nasional Hiu Pari Indonesia Ke-2 43-48 pp. https://d2d2tb15kqhejt.cloudfront.net /downloads/prosiding_hiu__pari_ta hun_ke_2_tahun_2018.pdf 
Quiros, A.L. 2007. Tourist compliance to a code of conduct and the resulting effects on whale shark (Rhincodon typus) behavior in Donsol, Philippines. Fish Res, 84(1): 102108.

https://doi.org/10.1016/j.fishres.2006 .11 .017

Rahman, A., J. Haryadi, A.A. Sentosa, \& Mujiyanto. 2017. Kajian awal kemunculan hiu paus (Rhicodon typus, Smith 1828) di Teluk Tomini dihubungkan dengan faktor fisik dan biologi perairan. J. Akuatika, 2: 128136.

https://doi.org/10.24198/jaki.v2i2.23 425

Reuchlin-Hugenholtz, E. \& E. McKenzie. 2015. Marine Protected Areas: Smart Investment in Ocean Health. WWF. Gland, Switzerland. 19 p. https://wwf.panda.org/?247781/Mari ne-Protected-Areas-SmartInvestments-in-Ocean-Health

Sandler, R. 2012. Intrinsic value, ecology, and conservation. Nature Education Knowledge, 3 (10): 4.

https://www.nature.com/scitable/kno wledge/library/intrinsic-valueecology-and-conservation-25815400/

Stacey, N., J. Karam, Dwyer, C. Speed, \& M. Meekan. 2008. Assessing traditional ecological knowledge of whale sharks (Rhincodon typus) in Eastern Indonesia: A pilot study with fishing communities in Nusa Tenggara Timur [report]. School for Environmental Research Charles Darwin University. https://www.environment.gov.au/syst em/files/resources/2afb66a0-aba6$4 \mathrm{c} 7 \mathrm{c}-85 \mathrm{~b} 4-$ 4f85bf11a974/files/assessing-whalesharks.pdf

Suruan, S.S., M. M. Kamal, R. Bawole, C. Tania, \& Mulyadi. 2018. Distribution of the whale shark population (Rhincodon typus, smith 1828) in Kwatisore waters, Nabire District, Papua Province. Prosiding Simposium Nasional Hiu Pari Indonesia Ke-2 23-32 pp. https://d2d2tb15kqhejt.cloudfront.net /downloads/prosiding_hiu__pari_ta hun_ke_2_tahun_2018.pdf

Thur, S.M. 2010. User fees as sustainable financing mechanisms for marine protected areas: an application to the Bonaire National Marine Park. Mar Pol, 34(1): 63-69. https://doi.org/10.1016/j.marpol.2009 .04 .008

Wolok, E. 2016. Analisis dampak ekonomi wisata hiu paus terhadap pendapatan masyarakat Botubarani Gorontalo. $J$. Ekonomi Bisnis dan Kewirausahaan, 5(2): 136-143. http://doi.org/10.26418/jebik.v5i2.17 146

Yulianda, F. 2019. Ekowisata perairan: Suatu konsep kesesuaian dan daya dukung wisata bahari dan wisata air tawar. IPB Press. Bogor (ID). 87 p.

Received : 12 August 2020

Reviewed : 08 October 2020

Accepted : 15 December 2020 